\title{
Identification of an 18-Methyl Derivative of Tacrolimus API in Streptomyces clavuligerus CKD-1119
}

\author{
Yun-Beom Ham ${ }^{\dagger}$ and Yoon-Mo Koo* \\ Department of Biological Engineering, Inha University, Incheon 402-751, Korea. *E-mail: ymkoo@inha.ac.kr \\ ${ }^{\dagger}$ ERC for Advanced BioSeparation Technology, Inha University, Incheon 402-751, Korea \\ Received September 17, 2010, Accepted October 26, 2010
}

\begin{abstract}
A new derivative of tacrolimus was evaluated for its molecular weight, using LC-MS of the tacrolimus bulk active pharmaceutical ingredient (API) recovered through the purification of crude tacrolimus produced by Streptomyces clavuligerus CKD-1119. In addition, the molecular weight of the new derivative of tacrolimus was found to be at $\mathrm{m} / \mathrm{z}$ 818 and was identified by ${ }^{13} \mathrm{C}-\mathrm{NMR}$ with peak assignments based on the differences in methyl group location resulting from the chemical structure. The structure of the new derivative, an unknown impurity of tacrolimus, was found to be 18-methyltacrolimus through comparison of the spectral data of the structural differences between ascomycin, tacrolimus, and the new derivative 18-methyltacrolimus.
\end{abstract}

Key Words: Tacrolimus (FK506), New derivative, LC-MS/MS, 18-Methyltacrolimus

\section{Introduction}

Tacrolimus (FK506) is a well-known potent immunosuppressant that is widely used in solid organ transplant patients for nearly 2 decades. ${ }^{1,2}$ Tacrolimus is a 23 -membered macrolide polyketide with very high immunosuppressive activity that was initially discovered in 1984 from the fermentation broth of the soil bacterium Streptomyces tsukubaensis by Fujisawa Healthcare Co. ${ }^{3}$ It was first approved by the Food and Drug Administration (FDA) in 1994 for use in the transplantation of the liver, bone marrow, and other organs. ${ }^{4}$ A bulk active pharmaceutical ingredient (API) should pass not only quality control test such as current good manufacturing practice (cGMP) but also should qualify for the specified threshold of a new impurity. Considering all these factors the control of impurities in pharmaceuticals is further open for isolating and identifying process-related impurities using mass spectrometry, nuclear magnetic resonance (NMR), high-performance liquid chromatography (HPLC) techniques to gain insight in the related field of the pharmaceutical industry. $^{5}$

Hence, we present the structural analysis of new derivative as an unknown impurity and it is very difficult to isolate due to their similar chemical structures ${ }^{5-7}$ from the tacrolimus bulk API recovered through the purification of crude tacrolimus during the fermentation of tacrolimus, the producing strain, Streptomyces clavuligerus CKD-1119, also produces ascomycin and dihydrotacrolimus. Chemical structure of tacrolimus and its related compounds is presented in Fig. 1. A number of liquid chromatography (LC) methods for quantifying macrolide immunosuppressants with ultraviolet (UV) or mass spectrometry (MS) detection have been reported. ${ }^{6,-10}$

An impurity profile is a description of the identified and unidentified impurities present in a typical batch of API produced through a specific controlled production process. It includes the identity or some qualitative analytical designation (e.g., retention time), the range, and the type of each identified impurity. For each API, there should be an impurity profile describing the identified and unidentified impurities present in a typical

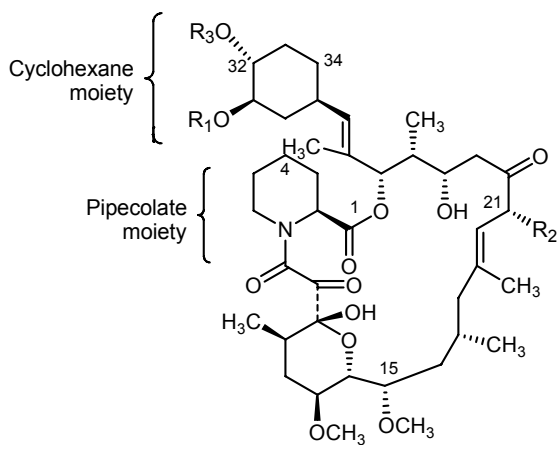

\begin{tabular}{|c|c|c|c|c|c|}
\hline Related Compounds & $\mathrm{R} 1$ & $\mathrm{R} 2$ & $\underline{\mathrm{R} 3}$ & $\begin{array}{c}\text { Average } \\
\text { M.W }\end{array}$ & $\begin{array}{c}\text { Monoisotopic } \\
\text { M.W }\end{array}$ \\
\hline Dihydrotacrolimus & $\mathrm{CH}_{3}$ & $\mathrm{CH}_{2}-\mathrm{CH}_{2}-\mathrm{CH}_{3}$ & $\mathrm{H}$ & 806.03 & 805.5 \\
\hline Ascomycin & $\mathrm{CH}_{3}$ & $\mathrm{CH}_{2}-\mathrm{CH}_{3}$ & $\mathrm{H}$ & 792.01 & 791.5 \\
\hline Tacrolimus & $\mathrm{CH}_{3}$ & Allyl & $\mathrm{H}$ & 804.02 & 803.5 \\
\hline
\end{tabular}

Figure 1. Structure of tacrolimus and its related compounds.

batch. The impurity profile is normally dependent on the process or origin of the API. ${ }^{11}$

A number of recent articles describe a designed approach and guide for isolating and identifying process-related impurities and degradation products via $\mathrm{MS}$, nuclear magnetic resonance (NMR), high-performance liquid chromatography (HPLC), and tandem MS for pharmaceutical substances. ${ }^{12,-14}$ In general, according to the International Conference on Harmonization (ICH) guidelines on impurities in new drug products, the identification of impurities below $0.1 \%$ is not considered necessary unless the potential impurities are expected to be unusually potent or toxic. In all cases, the impurities should be qualified. ${ }^{15}$

Due to its macrolide structure and lipophilic character, tacrolimus is a stable molecule, but an unknown impurity of tacrolimus was detected at the midpoint between the ascomycin and dihydrotacrolimus peaks on an HPLC chromatogram, as it was difficult to separate this impurity using the HPLC system (Fig. 2). 


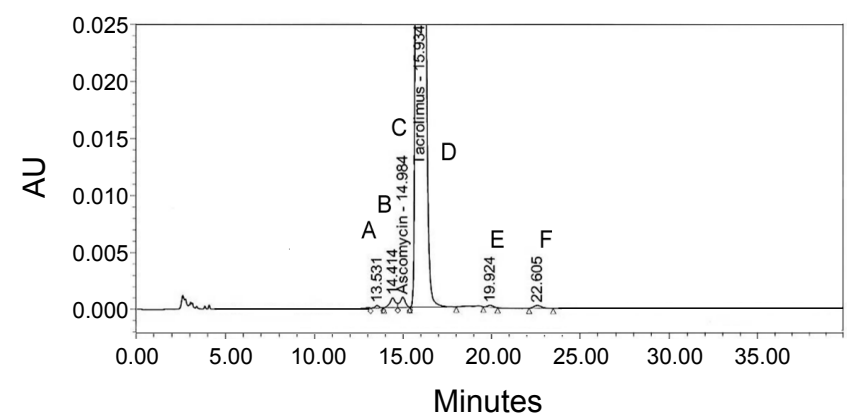

Figure 2. HPLC chromatogram of tacrolimus and its impurities. Two stainless steel columns in tandem, packed with dihydroxypropyl silanized silica gel, Supelcosil LC-Diol, $4.6 \times 250 \mathrm{~mm}, 5 \mu \mathrm{m}$ (Supelco Inc., Bellefonte, PA, USA), mobile phase; $n$-hexane: $n$-butyl chloride: acetonitrile; $7: 2: 1$. Note: if the temperature is too low, the mobile phase will separate into 2 layers and will become turbid; detector $225 \mathrm{~nm}$, column temperature ambient, $25^{\circ} \mathrm{C}$. A) $13.531 \mathrm{rt}$; dihydrotacrolimus, B) $14.414 \mathrm{rt}$; unknown impurity, C) $14.984 \mathrm{rt}$; ascomycin, D) 15.934 rt; tacrolimus, E) 19.924 rt; tautomer II, F) 22.605 rt; tautomer I.

\section{Experiment Methods}

Materials. HPLC-grade methanol, water, and reagent-grade formic acid (Merck KGaA, Darmstadt, Germany) were used to prepare the mobile phase. The tacrolimus reference standard (catalog \#1642802, current lot FOH135, CAS \#109581-93-3) was obtained from USPC, Inc. (Rockville, MD, USA). The tacrolimus standards and impurities were obtained from CKD Bio Corp. (Ansan city, Republic of Korea).

Equipment. A mass spectrometer (Synapt HDMS, Waters Ltd., Milford. Massachusetts, USA) fitted with a lock spray ion source was used. The instrument was operated in the electrospray-positive ionization mode and was directly coupled to the UPLC system. System control and data acquisition were performed with MassLynx 4.0 software.

Typical tuning conditions were as follows: electrospray capillary voltage, $3.1 \mathrm{kV}$; sample cone voltage, $35 \mathrm{~V}$. Source temperature, $100{ }^{\circ} \mathrm{C}$; desolvation temperature $300{ }^{\circ} \mathrm{C}$. Disolvation gas (nitrogen) flow: 5001/h.

UPLC conditions were as follows: column, Acquity BEH C18 $(1.7 \mu \mathrm{m} \times 100 \mathrm{~mm})$; mobile phase: $10 \%$ methanol $(0.1 \%$ formic acid, A), $80 \%$ methanol $(0.1 \%$ formic acid, B) at a flow rate of $0.4 \mathrm{~mL} / \mathrm{min}$ with gradient system; column oven temperature, $40{ }^{\circ} \mathrm{C}$, auto sampler temperature; $10^{\circ} \mathrm{C}$, injection volume; $2 \mu \mathrm{L}(\mathrm{C} 1,000 \mu \mathrm{g} / \mathrm{mL})$.

NMR spectrometer (advance NMR spectrometer, Bruker, $400 \mathrm{MHz}$ ) was used with ${ }^{1} \mathrm{H},{ }^{13} \mathrm{C}$ nucleous and chloroform-d were used as dissolution solvents. To establish the analytical conditions of the unknown derivative powder (purity: 90\%, 15 $\mathrm{mg}$ ), the previous studies on structural analysis were used as reference. 6,7

\section{Results and Discussion}

LC-MS Analysis of an Unknown Impurity. A total ion chromatogram of the unknown impurity by LC-MS is shown in Fig. 3.

The results of the LC-MS/MS analysis of tacrolimus re-

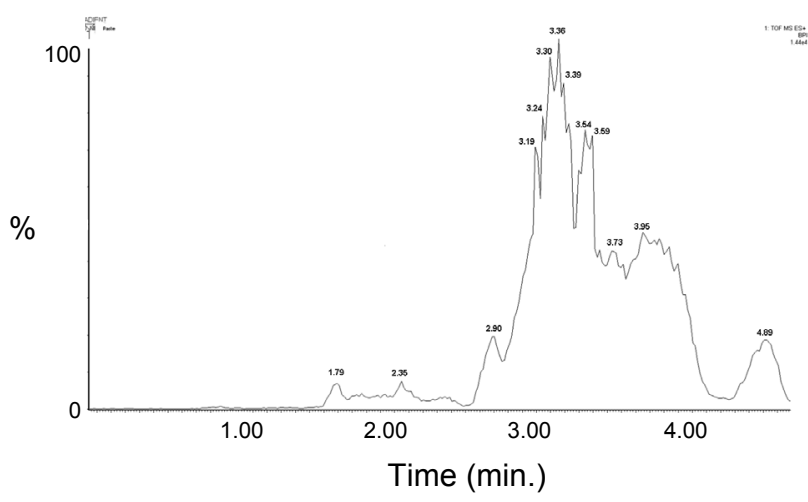

Figure 3. Total ion chromatogram of unknown impurity by LC-MS. UPLC conditions. Column: Acquity BEH C18 $(1.7 \mu \mathrm{m}, 2.1 \times 100 \mathrm{~mm})$; mobile phase: $10 \%$ methanol containing $0.1 \%$ formic acid. (A), $90 \%$ methanol containing $0.1 \%$ formic acid, column oven temperature: $40{ }^{\circ} \mathrm{C}$, auto sampler temperature: $10^{\circ} \mathrm{C}$, gradient condition: $\mathrm{A} / \mathrm{B}(60 / 40)$, initial time $\sim 1.5 \mathrm{~min} \rightarrow \mathrm{A} / \mathrm{B}(40 / 60), 1.5 \mathrm{~min} \sim 3.5 \mathrm{~min} \rightarrow \mathrm{A} / \mathrm{B}(20 / 80)$, $3.5 \mathrm{~min} \sim 4.0 \mathrm{~min}, \mathrm{~A} / \mathrm{B}(60 / 40), 4.0 \mathrm{~min} \sim 5.0 \mathrm{~min}$, injection volume: $2 \mu \mathrm{L}(\mathrm{C} 1,000 \mu \mathrm{g} / \mathrm{mL})$, MS conditions. System: Synapt HDMS TOF, mass source: ESI (with lock spray interface), PosMS source parameters: capillary $(\mathrm{kV}): 3.1$, cone voltage $(\mathrm{V}): 35$, source temperature $\left({ }^{\circ} \mathrm{C}\right): 100$, desolvation temperature $\left({ }^{\circ} \mathrm{C}\right): 300$, desolvation gas flow (L/Hr): 500.

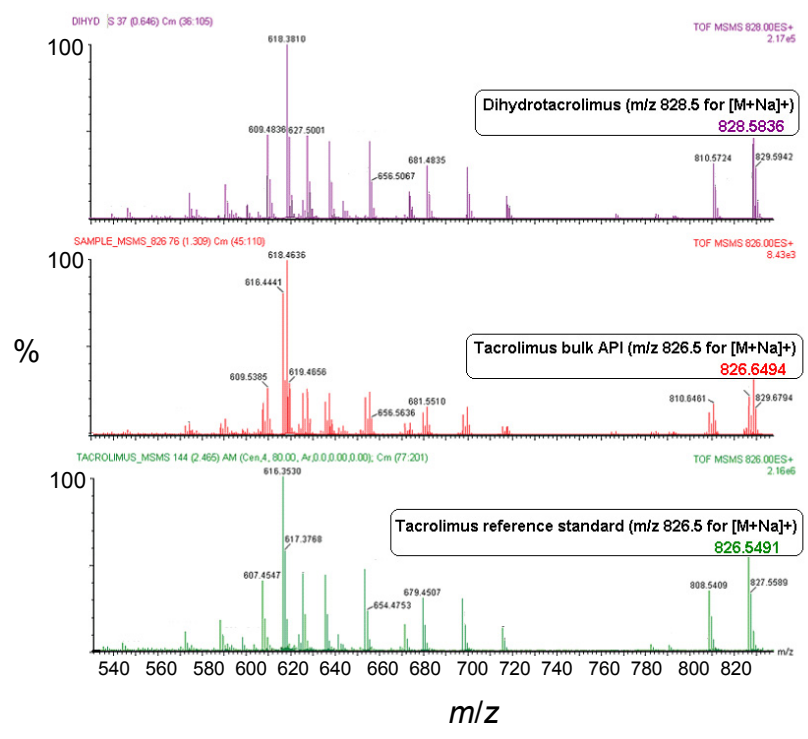

Figure 4. LC-ESI-tandem spectra of dihydrotacrolimus $(\mathrm{m} / \mathrm{z} 828.5$ for $\left.[\mathrm{M}+\mathrm{Na}]^{+}\right)$, tacrolimus bulk API $\left(\mathrm{m} / \mathrm{z} 826.5\right.$ for $\left.[\mathrm{M}+\mathrm{Na}]^{+}\right)$and its reference standard $\left(\mathrm{m} / \mathrm{z} 826.5\right.$ for $\left.[\mathrm{M}+\mathrm{Na}]^{+}\right)$. TOF Mode (LC-MS/MS) Exact mass: 3 ppm, high resolution: over 17,500 FWHM. High sensitivity: Class-leading sensitivity, features enhanced duty cycle (EDC) capability for maximum duty cycle over specified $\mathrm{m} / \mathrm{z}$ range. Dynamic range: up to 4 orders of linearity LC ready acquisition rates: up to 10 spectra/sec LC/MSE: High-definition metabolite and protein profiling. Note: injection volume of these 3 samples is $2 \mu \mathrm{L}(\mathrm{C} 1,000 \mu \mathrm{g} / \mathrm{mL})$, respectively.

ference standard, bulk API and dihydrotacrolimus are shown in Fig. 4. A positive tacrolimus ion was found to be at $\mathrm{m} / \mathrm{z} 826$ for $[\mathrm{M}+\mathrm{Na}]^{+}$and was predicted to have a molecular weight of 804.

A positive ion of the unknown impurity was found to be at $m / z 840$ for $[\mathrm{M}+\mathrm{Na}]^{+}$, and its molecular weight was predicted 


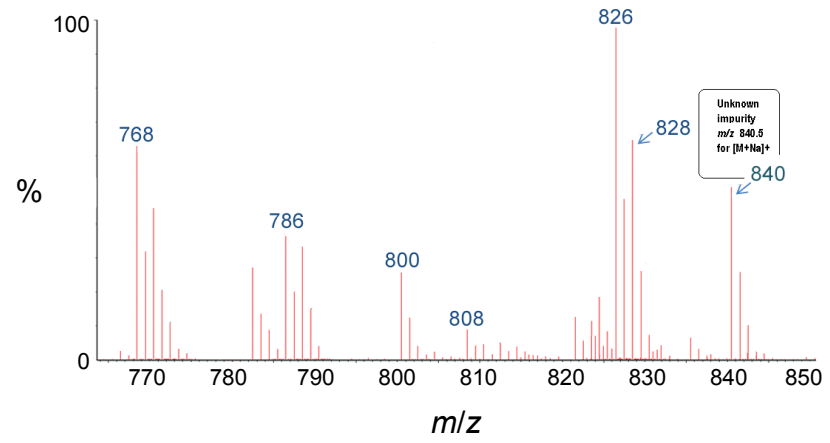

Figure 5. LC-MS/MS spectrum of unknown impurity $(\mathrm{m} / \mathrm{z} 840.5$ for $\left.[\mathrm{M}+\mathrm{Na}]^{+}\right)$. Mobility-TOF Mode Triwave provides access to the unique benefits of high-efficiency IMS. Oa-TOF: High acquisition rates complement IMS separation timeframes. Time Aligned Parallel (TAP) fragmentation provides comprehensives first- and second-generation structural information in a single experiment. HDC mode enables significant sensitivity enhancements over a wide $\mathrm{m} / \mathrm{z}$ range. Drift scope mobility environment: interactive visualization and manipulation of multidimensional data.

to be 818 (Fig. 5) The molecular weight of the unknown impurity was obtained through the analysis of tacrolimus, where the difference in molecular weight was predicted to be 14 , as was evident. Therefore, in this article report, it was expected that only the $\mathrm{CH}_{2}(\mathrm{~m} / \mathrm{z} 14)$ group could be combined with the tacrolimus analogue; its methyl derivative was determined to be $\mathrm{C}_{45} \mathrm{H}_{71} \mathrm{NO}_{11}$.

NMR Analysis of Tacrolimus and Ascomycin. The unknown tacrolimus impurity is similar to the fermentation products tacrolimus and ascomycin. The structures of these 2 compounds were identified and compared via NMR spectroscopy. The NMR data of tacrolimus and ascomycin have been published in previous papers. ${ }^{6}$ Sample analysis was performed with $\mathrm{CHCl}_{3}-\mathrm{d}$ solvent conditions. Ascomycin, an active tacrolimus analog in which the $\mathrm{C} 21$ allyl group is replaced by an ethyl group, is produced mainly by the fermentation of the streptomycetes strain. To confirm the differences between the 3 compounds, NMR analysis was performed so that values could be assigned to tacrolimus and ascomycin in the NMR spectra.

Analysis of the Unknown Impurity Structure. Tacrolimus has 8 quartets, 13 triplets, 16 doublets, and 7 singlets with the same composition as that observed in ascomycin, and evidence associated with the structure of the unknown impurity was obtained from the NMR spectra. In ascomycin, the vinyl group found in tacrolimus was replaced with an ethyl group with the molecular formula $\mathrm{C}_{43} \mathrm{H}_{69} \mathrm{NO}_{12}$. Tacrolimus and ascomycin were compared with the ${ }^{13} \mathrm{C}$-NMR data, new peaks were observed at $11.58 \mathrm{ppm}(\mathrm{q})$ and $25.90 \mathrm{ppm}(\mathrm{t})$, whereas the peaks at $35.38 \mathrm{ppm}(\mathrm{t}), 115.96 \mathrm{ppm}(\mathrm{t})$, and $136.15 \mathrm{ppm}(\mathrm{s})$ were no longer present. This was attributed to the replacement of the tacrolimus vinyl group with the methyl group, found in ascomycin. In the analysis of the unknown impurity, we considered the fact that fresh ascomycin from the $11.58 \mathrm{ppm}(\mathrm{q})$ and 25.90 ppm $(\mathrm{t})$ data, which lacked tacrolimus, had no significant changes to the vinyl group. This suggested that the ascomycin that disappeared from the $35.38 \mathrm{ppm}(\mathrm{t}), 115.96 \mathrm{ppm}(\mathrm{t})$, and 136.15 ppm (s) peaks still existed, since there was no change in the vinyl

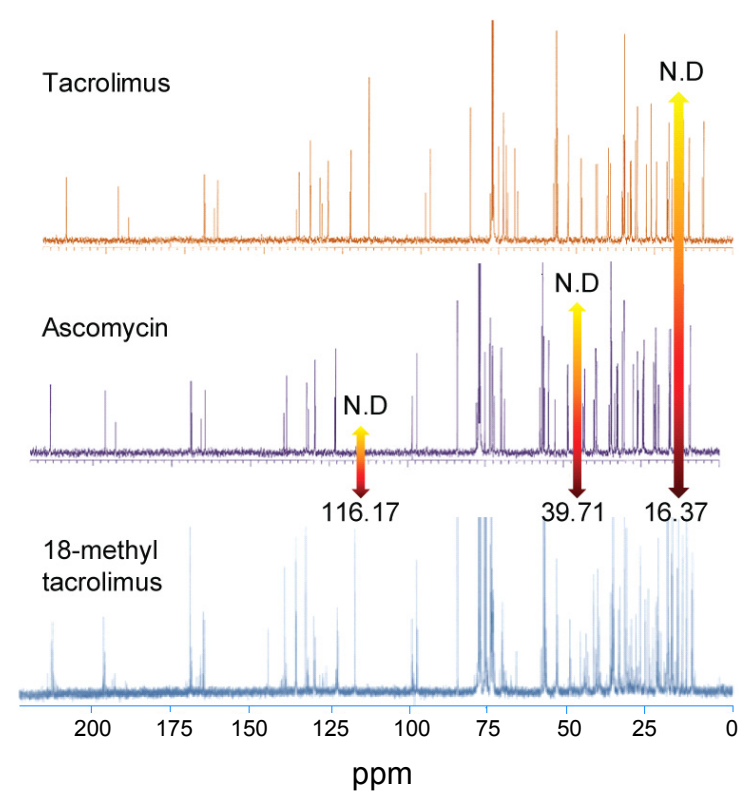

Figure 6. ${ }^{13} \mathrm{C}$-NMR spectra of tacrolimus, ascomycin and 18-methyltacrolimus.

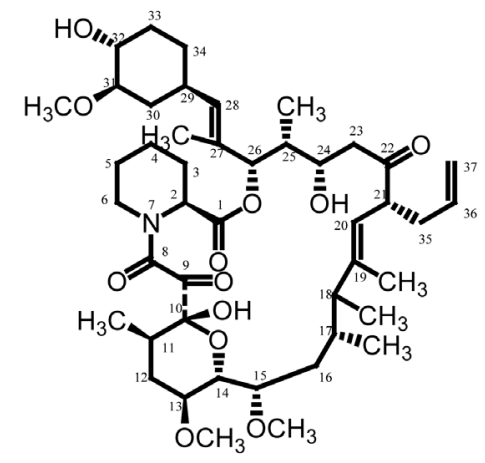

Figure 7. Structure of 18-methyltacrolimus as an unknown impurity of tacrolimus.

Table 1. ${ }^{13} \mathrm{C}-\mathrm{NMR}$ assignments for tacrolimus, its unknown impurity, and ascomycin on the ${ }^{13} \mathrm{C}$-NMR spectrum $(\delta$ : ppm, internal standard: TMS in DMSO).

\begin{tabular}{cccc}
\hline Carbon No. & Tacrolimus & Ascomycin & 18-methyltacrolimus \\
\hline $18-\mathrm{CH}_{3}$ & N.D & N.D & 16.37 \\
18 & 47.01 & N.D & 39.71 \\
35 & 35.38 & 25.9 & 35.48 \\
36 & 136.15 & 11.58 & 136.22 \\
37 & 115.96 & N.D & 116.17 \\
\hline
\end{tabular}

group. However, in the newly formed peaks at $16.37 \mathrm{ppm}$ (q) and $39.71 \mathrm{ppm}(\mathrm{d})$, and the $47.01 \mathrm{ppm}(\mathrm{t})$ peak, ascomycin disappeared as the methylene group was substituted with a methyl group (Fig. 6). The methylene group can be substituted with a methyl group at 11 positions, and in the methylene and methylcontaining derivative, the structure of the vinyl group in tacrolimus was complete, except for a triplet. The $16.37 \mathrm{ppm}$ (q) and $39.71 \mathrm{ppm}$ (d) peaks, however, were formed, whereas the new 47.01 ppm (t) peak was lost, with only 1 substitution, as 
shown in Table 1, and the tacrolimus structure appeared with another methyl group. The structure of the ascomycin vinyl group was found to be the same as that of ascomycin, and the tacrolimus methyl group was newly formed. Therefore, the molecular formula of the unknown impurity was determined to be $\mathrm{C}_{45} \mathrm{H}_{71} \mathrm{NO}_{12}$, with a molecular weight of 818 .

Chemical structure of the unknown tacrolimus impurity is presented in Fig. 7.

\section{Conclusion}

The unknown impurity was identified as 18-methyltacrolimus. The structural differences were determined through a structural analysis of ascomycin and tacrolimus using ${ }^{13} \mathrm{C}-\mathrm{NMR}$ assignments. Through LC-MS/MS analysis, the results of the molecular information were combined, and it was found that 18-methyltacrolimus has not yet been reported. The molecular formula of the unknown impurity was determined to be $\mathrm{C}_{45}$ $\mathrm{H}_{71} \mathrm{NO}_{12}$, with a molecular weight of 818 .

The spectrum data also showed that 18-methyltacrolimus, identified through LC-MS/MS analyses, can be used to determine the structural differences between tacrolimus and ascomycin. These differences were determined on the basis of the
${ }^{13} \mathrm{C}$-NMR peak assignments by following the location of the methyl group identified by analysis of the chemical structure.

\section{References}

1. Yu-Luan, C.; Hirabayashi, H., et al. J. Chromatogr. B 2006, 830, 330.

2. Muramarsu, H.; Mokhtar, S. I., et al. Actiomycetologica. 2005, 19 , 33.

3. Tanka, H.; Kuroda, A., et al. J. Am. Chem. Soc. 1987, 109, 5031.

4. Park, J. W.; Mo, S. J., et al. Anal. Biochem. 2009, 393, 1.

5. Jiben, R. AAPS PharmSciTech. 2002, 3, 2; available at: http:// www.aapspharmscitech.org.

6. Namiki, Y.; Kihara, N., et al. J. Antbiot. 1993, 46, 1149.

7. Tanaka, H.; Nakahara, K., et al. J. Antibiot.1997, 50, 418.

8. Motamedi, H.; Shafiee. A., et al. J. Biochem. 1998, 256, 528.

9. Dai, Y.; Hebert, M. F., et al. Drug Metab. Dispos. 2006, 34, 836.

10. Bogusz, M. J.; Enazi, H. J., et al. J. Chromatogr. B. 2007, 850, 471.

11. Salm, P.; Taylor, P. J., et al. Ther. Drug Monit. 2008, 30, 292.

12. Sanjay, B.; Bharati, R., et al. Eurasian J. Anal. Chem. 2007, 2, 1.

13. Alsante, K. M.; Hatajik, T. D., et al. Am. Pharm. Rev. 2001, $4,1$.

14. Lohr, L. L.; Sharp, T. R. et al. Am. Pharm. Rev. Fall issue 2001; available at: http://:www.americanpharmaceuticalreview.com/ past_articles_f.htm.

15. Winger, B. E.; Kemp, C. A. J. Am. Pharm. Rev. Summer issue 2001; available at: http://:www.americanpharmaceuticalreview. com/past_articles_f.htm. 